\title{
Identification of a New HIV-1 BC Intersubtype Circulating Recombinant Form (CRF108_BC) in Spain
}

\author{
Javier E. Cañada ${ }^{1}{ }^{\mathbb{C}}$, Elena Delgado ${ }^{1}$, Horacio Gil ${ }^{1}{ }^{\circledR}$, Mónica Sánchez ${ }^{1}$, Sonia Benito ${ }^{1}$, Elena García-Bodas ${ }^{1}$, \\ Carmen Gómez-González ${ }^{2}$, Andrés Canut-Blasco ${ }^{2}$, Joseba Portu-Zapirain ${ }^{3}$, Ester Sáez de Adana ${ }^{4}$, \\ Mireia De la Peña ${ }^{5}$, Sofía Ibarra ${ }^{5}\left({ }^{\circ}\right.$, Gustavo Cilla ${ }^{6}$, José Antonio Iribarren ${ }^{7}{ }^{\circ}$, Ana Martínez-Sapiña ${ }^{8}$ \\ and Michael M. Thomson ${ }^{1, *}$
}

1 HIV Biology and Variability Unit, Centro Nacional de Microbiología, Instituto de Salud Carlos III, Majadahonda, 28220 Madrid, Spain; jecanada@isciii.es (J.E.C.); delgade@isciii.es (E.D.); hgil@isciii.es (H.G.); monicasanchez@isciii.es (M.S.); sbenito@isciii.es (S.B.); egbodas@isciii.es (E.G.-B.)

2 Department of Microbiology, Hospital Universitario Araba, 01009 Vitoria-Gasteiz, Spain; carmen.gomezgonzalez@osakidetza.eus (C.G.-G.); andres.canutblasco@osakidetza.eus (A.C.-B.)

3 Bioaraba, Infectious Diseases Research Group, 01009 Vitoria-Gasteiz, Spain; josejoaquin.portuzapirain@osakidetza.eus

4 Department of Infectious Diseases-Internal Medicine, Hospital Universitario Araba, 01009 Vitoria-Gasteiz, Spain; ester.saezdeadanaarroniz@osakidetza.eus

5 Department of Infectious Diseases, Hospital Universitario Basurto, 48013 Bilbao, Spain; mireia.delapenatrigueros@osakidetza.eus (M.D.l.P.); sofia.ibarraugarte@osakidetza.eus (S.I.)

check for updates

Citation: Cañada, J.E.; Delgado, E.; Gil, H.; Sánchez, M.; Benito, S.; García-Bodas, E.; Gómez-González, C.; Canut-Blasco, A.; Portu-Zapirain, J.; Sáez de Adana, E.; et al. Identification of a New HIV-1 BC Intersubtype Circulating Recombinant Form (CRF108_BC) in Spain. Viruses 2021, 13, 93. https://doi.org/10.3390/ v13010093

Academic Editors: William M.M. Switzer and

Dimitrios Paraskevis

Received: 15 December 2020

Accepted: 8 January 2021

Published: 12 January 2021

Publisher's Note: MDPI stays neutral with regard to jurisdictional clai$\mathrm{ms}$ in published maps and institutional affiliations.

Copyright: $@ 2021$ by the authors. Licensee MDPI, Basel, Switzerland. This article is an open access article distributed under the terms and conditions of the Creative Commons Attribution (CC BY) license (https:// creativecommons.org/licenses/by/ $4.0 /)$.
6 Biodonostia, Department of Microbiology, Hospital Universitario Donostia, 20080 San Sebastián, Spain; carlosgustavosantiago.cillaeguiluz@osakidetza.eus

7 Biodonostia, Department of Infectious Diseases, Hospital Universitario Donostia, 20080 San Sebastián, Spain; joseantonio.iribarrenloyarte@osakidetza.eus

8 Department of Microbiology, Hospital Universitario Miguel Servet, 50009 Zaragoza, Spain; amartinezsa@salud.aragon.es

* Correspondence: mthomson@isciii.es; Tel.: +34-918-223-900

\begin{abstract}
The extraordinary genetic variability of human immunodeficiency virus type 1 (HIV-1) group $\mathrm{M}$ has led to the identification of 10 subtypes, 102 circulating recombinant forms (CRFs) and numerous unique recombinant forms. Among CRFs, 11 derived from subtypes $B$ and $C$ have been identified in China, Brazil, and Italy. Here we identify a new HIV-1 CRF_BC in Northern Spain. Originally, a phylogenetic cluster of 15 viruses of subtype $C$ in protease-reverse transcriptase was identified in an HIV-1 molecular surveillance study in Spain, most of them from individuals from the Basque Country and heterosexually transmitted. Analyses of near full-length genome sequences from six viruses from three cities revealed that they were $\mathrm{BC}$ recombinant with coincident mosaic structures different from known CRFs. This allowed the definition of a new HIV-1 CRF designated CRF108_BC, whose genome is predominantly of subtype $C$, with four short subtype B fragments. Phylogenetic analyses with database sequences supported a Brazilian ancestry of the parental subtype $\mathrm{C}$ strain. Coalescent Bayesian analyses estimated the most recent common ancestor of CRF108_BC in the city of Vitoria, Basque Country, around 2000. CRF108_BC is the first CRF_BC identified in Spain and the second in Europe, after CRF60_BC, both phylogenetically related to Brazilian subtype C strains.
\end{abstract}

Keywords: HIV-1; circulating recombinant form; HIV-1 genetic diversity; HIV-1 phylogeny; HIV-1 molecular epidemiology

\section{Introduction}

HIV-1 is characterized by high mutation and recombination rates, which have led to the generation of extraordinary genetic diversity. Four HIV-1 groups have been characterized: M, N, O, and P. Group M, the oldest lineage [1,2], is the causative of the global pandemic and is subdivided into ten subtypes $(\mathrm{A}-\mathrm{D}, \mathrm{F}-\mathrm{H}, \mathrm{J}-\mathrm{L})$, of which subtype $\mathrm{C}$ is the most prevalent worldwide, circulating mainly in Southern and East Africa, India, 
and Southern Brazil, and subtype B are the most prevalent in Western Europe and the Americas [3].

Recombination between subtypes has led to the generation of circulating and unique recombinant forms (CRFs and URFs, respectively), which represent around $23 \%$ of HIV-1 strains worldwide [3]. To define a CRF, at least three HIV-1 near full-length genomes (NFLGs) must be characterized from epidemiologically unlinked individuals, showing identical mosaic patterns and clustering in phylogenetic trees apart from previously defined CRFs [4]. To date, a total of 102 CRFs have been reported in the literature.

HIV-1 was introduced in Western Europe in the early 1980s among men who have sex with men (MSM) and persons who inject drugs (PWID) infected with viruses of subtype $B$, which is the current predominant genetic form $(67.2 \%)$, followed by subtype $C$ (5.3\%) [5]. Among non-subtype B clades, there are several CRFs first identified in Western Europe: CRF04_cpx [6], CRF14_BG [7,8], CRF42_BF [9], CRF47_BF [10], CRF50_A1D [11], CRF56_cpx [12], CRF60_BC [13,14], CRF73_BG [15], CRF94_cpx [16] and CRF98_06B [17].

In this study, we report the first CRF_BC identified in Spain and the second in Europe, estimating its most probable origin by phylogeographic and phylodynamic analyses.

\section{Materials and Methods}

\subsection{Patients}

Plasma or whole blood samples were collected in 1999-2020 from more than 13,000 HIV-1-infected individuals from 10 Spanish regions for determination of antiretroviral drug resistance mutations and for molecular epidemiological surveillance of HIV-1.

\subsection{Nucleic Acid Extraction, Amplification and Sequencing}

RNA was extracted from $1 \mathrm{~mL}$ plasma using NucliSENS ${ }^{\circledR}$ EasyMAG $^{\circledR}$ (bioMérieux, Marcy l'Etoile, France). DNA was extracted from $200 \mu \mathrm{L}$ whole blood using QIAamp ${ }^{\circledR}$ DNA DSP blood mini kit (Qiagen, Hilden, Germany), following the manufacturer's instructions. A protease-reverse transcriptase (PR-RT) fragment of pol (HXB2 positions 2253-3629) was amplified by RT-PCR followed by nested-PCR from RNA or by nested-PCR from DNA, as previously described [18].

NFLGs were amplified from plasma RNA, with PR-RT previously sequenced, through RT-PCR followed by nested-PCR in five overlapping fragments, as reported previously in $[7,19]$ and modified from [20]. The amplification strategy is schematically depicted in Figure S1, and PCR primers are listed in Table S1. Sequencing was done with an automated capillary sequencer. Fifteen PR-RT, six NFLG, and one semigenome sequence were deposited in GenBank (Table 1).

Table 1. Epidemiological and clinical data of the patients and GenBank accessions of sequences.

\begin{tabular}{|c|c|c|c|c|c|c|c|c|c|c|}
\hline Sample & City & Region * & $\begin{array}{l}\text { Country } \\
\text { of } \\
\text { Origin }\end{array}$ & $\begin{array}{l}\text { Year of } \\
\text { Diagno- } \\
\text { sis }\end{array}$ & $\begin{array}{l}\text { Year of } \\
\text { Collec- } \\
\text { tion }\end{array}$ & Genc & Age & $\begin{array}{l}\text { Transmission } \\
\text { Route }+\end{array}$ & $\begin{array}{c}\text { PR-RT } \\
\text { GenBank } \\
\text { Accession }\end{array}$ & $\begin{array}{c}\text { NFLG } \\
\text { GenBank } \\
\text { Accession }\end{array}$ \\
\hline P1363 & Vitoria & Basque C. & Spain & 2006 & 2010 & $\mathrm{M}$ & 64 & Het & MT436238 & - \\
\hline P1607 & Vitoria & Basque C. & Brazil & 2007 & 2007 & $\mathrm{~F}$ & 20 & Trans & MT436239 & - \\
\hline P2085 & Vitoria & Basque $C$. & Spain & 2008 & 2008 & $\mathrm{M}$ & 40 & Het & MT559129 & - \\
\hline P2782 & San Sebastián & Basque C. & Spain & 2011 & 2011 & $\mathrm{M}$ & 38 & Het & MT436240 & - \\
\hline P2969 & San Sebastián & Basque C. & Spain & 2011 & 2011 & $\mathrm{~F}$ & 32 & Het & MT436241 & - \\
\hline P3536 & Bilbao & Basque C. & Spain & 2013 & 2013 & $\mathrm{M}$ & 70 & Het & MT436242 & MT559130 \\
\hline P4439 & Vitoria & Basque C. & Spain & 2016 & 2016 & $\mathrm{~F}$ & 58 & Het & MT436244 & MN172222 \\
\hline P4517 & Vitoria & Basque $C$. & Spain & 2010 & 2016 & M & 58 & n.a. & MT436245 & - \\
\hline P4523 & Bilbao & Basque C. & Spain & 2016 & 2016 & M & 42 & Het & MT436246 & MT559131 \\
\hline P4697 & Vitoria & Basque $C$. & Spain & 2017 & 2017 & $\mathrm{~F}$ & 28 & Het & MT436247 & MT559132 \\
\hline P4719 & Vitoria & Basque C. & Spain & 2017 & 2017 & M & 44 & Het & MT436248 & - \\
\hline P4977 & Vitoria & Basque $C$. & Spain & 2018 & 2018 & M & 53 & Het & MT436249 & MN172223 \\
\hline P5007 & Vitoria & Basque C. & Spain & 2018 & 2018 & M & 35 & Het & MT436250 & MN172224 \\
\hline P5236 & Vitoria & Basque C. & Spain & 2019 & 2019 & $\mathrm{~F}$ & 65 & Het & MT436251 & - \\
\hline Z0230 & Zaragoza & Aragon & Spain & 2017 & 2017 & M & 36 & MSM & MT436252 & MN172225 \\
\hline
\end{tabular}

\footnotetext{
* Basque.C.: Basque Country. † Het: heterosexual; MSM: men who have sex with men; Trans: transsexual; n.a.: not available. $\ddagger$ Semigenome.
} 


\subsection{Phylogenetic Analyses}

Initial phylogenetic analyses were performed with FastTree v2.1 [21] with more than 16,000 HIV-1 PR-RT sequences obtained in our laboratory from more than 13,000 individuals whose samples were collected in Spain in 1999-2020, similar sequences retrieved through BLAST searches [22] from the Los Alamos HIV Sequence Database [23], and subtype and CRF references. For these analyses, the general time-reversible with CAT approximation for rate heterogeneity among sites (GTR + CAT) substitution model was used, with the assessment of node support with Shimodaira-Hasegawa (SH)-like local support values.

Subsequent maximum-likelihood (ML) analyses were performed with W-IQ-Tree [24], including sequences similar to the identified cluster, retrieved from the HIV Sequence Database [23] through BLAST searches [22]. These analyses were performed with a $1200 \mathrm{nt}$ fragment of the PR-RT region (HXB2 positions 2253-3452). The substitution model was GTR with gamma-distributed heterogeneity across sites, allowing for a proportion of invariant sites $(\mathrm{GTR}+\mathrm{G}+\mathrm{I})$, and node support was assessed through ultrafast bootstrapping with 1000 replicates.

The recombination patterns in NFLGs were determined by bootscanning [25] using Simplot v.3.5.1 [26], including HIV-1 subtype references downloaded from the Los Alamos HIV Sequence Database, with a $250 \mathrm{nt}$ window moving in $20 \mathrm{nt}$ steps and trees constructed with the neighbor-joining method and Kimura 2-parameter substitution model. Breakpoints were located more precisely through sequence inspection by determining the segment where similarity of the BC recombinants with NFLG genomes of subtype B and Brazilian subtype $C$ viruses changed between clades. Breakpoints were located at the midpoint between two adjacent subtype-discriminating nucleotides (defined as those differing between subtype consensuses and present in $>75 \%$ viruses of one of the parental clades and in $<10 \%$ of the other) where similarity changed between subtypes.

\subsection{Phylogeographic and Phylodynamic Analyses}

The time and location of the most recent common ancestor (MRCA) were estimated with the Bayesian coalescent Markov Chain Monte Carlo (MCMC) method, implemented in BEAST v1.10.4 [27], summarizing the set of trees of the posterior distribution in a maximum clade credibility (MCC) tree. PR-RT sequences $(1.2 \mathrm{~kb})$ of the identified cluster were used, labeled with the location and the year of collection of the sample. Fifty subtype $C$ sequences from different countries and collection years were included to provide a temporal signal, previously assessed with TempEst v1.5.1 [28]. We chose an HKY substitution model with gamma-distributed among-site rate heterogeneity and two partitions in codon positions (1st $+2 n d ; 3 r d)$ [29]. A Bayesian skyline coalescent model was chosen with a lognormal uncorrelated relaxed clock model. Uniform priors were used for absolute substitution rates (0-0.02 sub/site/year). MCMC analyses were run for 70 million generations, sampling every 4000 generations. Tracer v1.7.1 [30] was used to check MCMC convergence, ensuring effective sample sizes (ESS) of all parameters above 200 [30]. Trees were visualized with FigTree v.1.3.1 (Rambaut, http://tree.bio.ed.aC.uk/software/figtree/).

\subsection{Antiretroviral Drug Resistance Analysis}

Antiretroviral drug resistance was analyzed with the HIVdb program at Stanford University's HIV Drug Resistance Database [31].

\section{Results}

\subsection{PR-RT Sequence Analyses}

The phylogenetic analyses of HIV-1 PR-RT sequences from our cohort identified a monophyletic cluster of 15 viruses of subtype $C$ supported by an SH-like value of 1 , which was designated C_2. The ML tree constructed with W-IQ-Tree, including sequences retrieved from databases through BLAST similarity searches, revealed no additional viruses branching within the cluster and its relationship to viruses of the subtype $C$ strain circu- 
lating in Brazil (Figure 1). Epidemiological and clinical data of the 15 patients of the C_2 cluster are summarized in Table 1. Most of them were Spanish, except a Brazilian individual, and were diagnosed with HIV-1 infection from 2006 to 2019 in the Basque Country (10 in the city of Vitoria), except one patient diagnosed in Zaragoza. Ten patients were men, and 5 were women; heterosexual transmission was reported in $12(80 \%)$ infections, and one patient was a self-reported MSM.

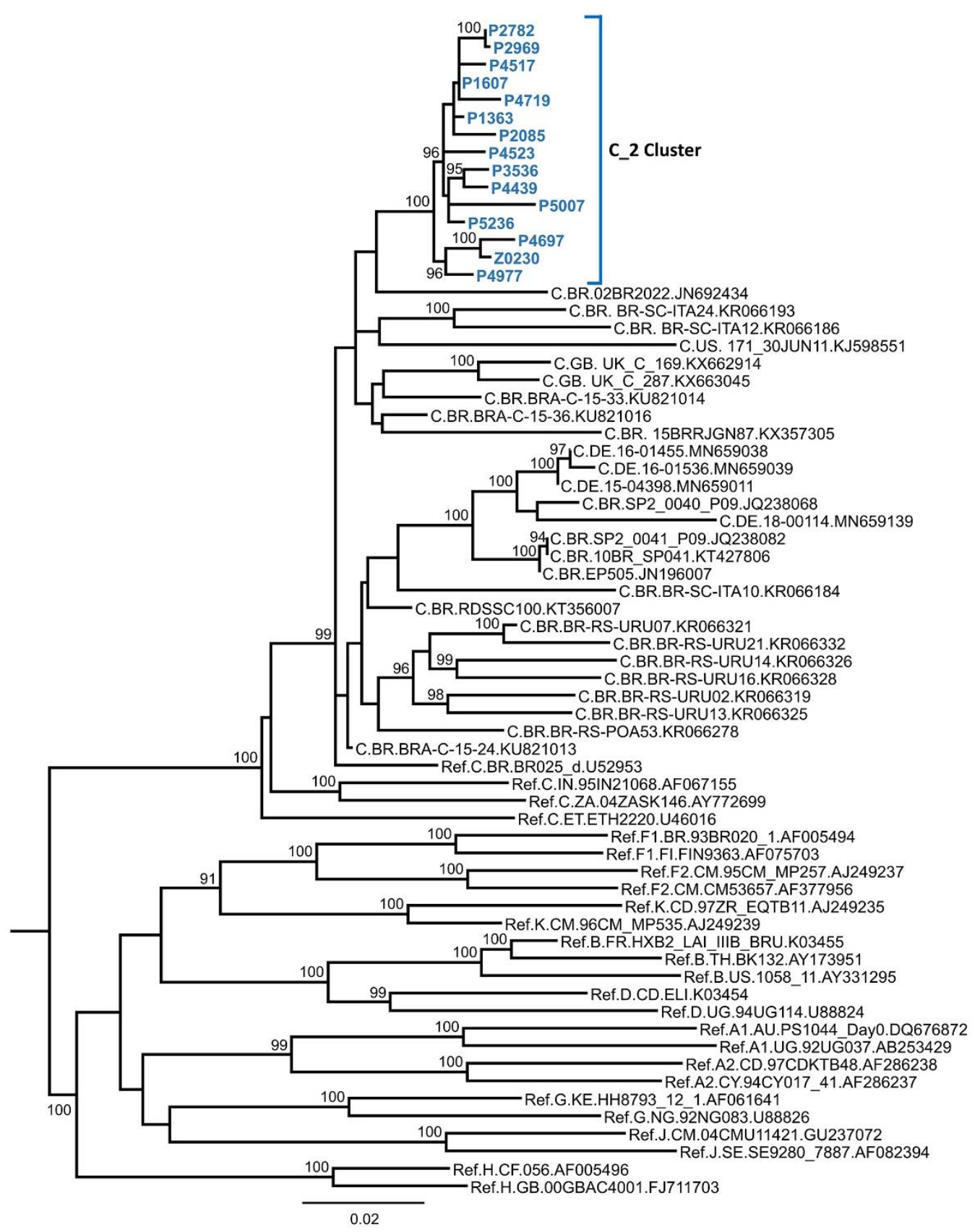

Figure 1. Maximum likelihood tree of C_2 cluster. Similar sequences retrieved from databases and subtype references are also included. Only bootstrap values $\geq 90 \%$ are shown. Sequences obtained in our laboratory are in blue and bold type. Database sequences are labeled with subtype, two-letter ISO code of the country of collection, virus names, and GenBank accession. Subtype reference sequences are labeled with "Ref.".

No antiretroviral drug resistance mutations were found in any of the PR-RT sequences. 


\subsection{NFLG Sequence Analyses}

To determine whether the viruses grouping in C_2 were of uniform subtype along their genomes or recombinant, six NFLG sequences and a semigenome obtained from viruses collected in three cities were analyzed by bootscanning. The analyses showed that the viruses were $\mathrm{BC}$ recombinant, with eight breakpoints delimiting four short subtype $\mathrm{B}$ fragments, located in pol, pol-vif overlap, vif-vpr-tat overlap, and nef, respectively, in a genome predominantly of subtype C (Figure 2A). The mosaic structure inferred from the bootscan analyses complemented with sequence inspection to define more precisely breakpoint locations is shown in Figure 2B. In an ML phylogenetic tree, all six newly derived NFLG of the BC recombinant viruses are grouped in a cluster separate from previously identified CRF_BCs (Figure 3). These results allow defining a new HIV-1 CRF, which was designated CRF108_BC. Comparison of CRF108_BC's mosaic structure with those of previously identified CRF_BCs is shown in Figure S2.

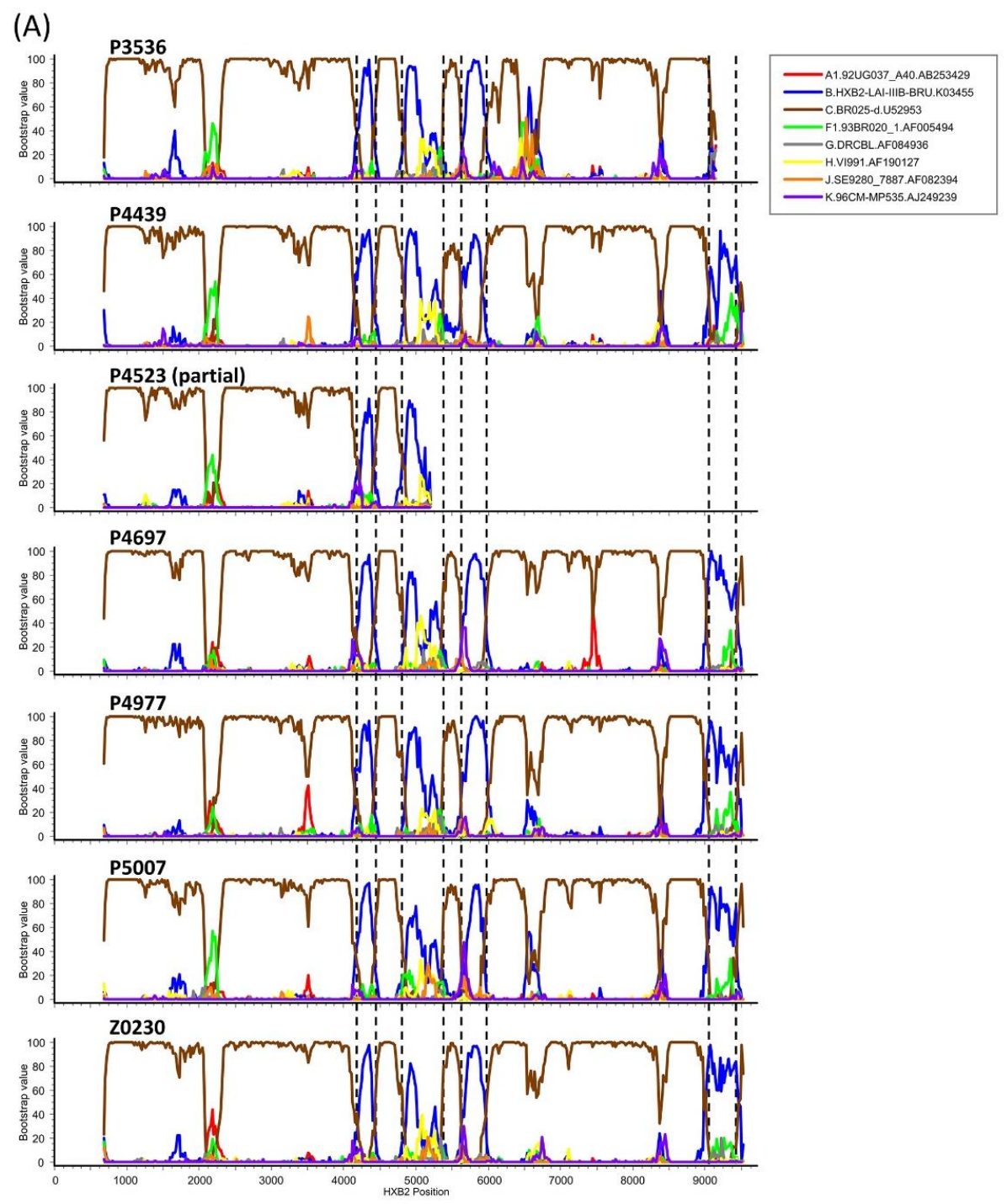

(B)

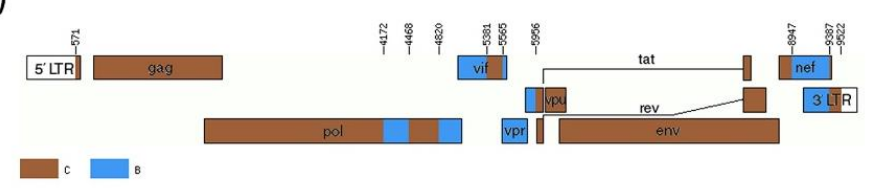

Figure 2. (A) Bootscan analyses of 6 NFLG and 1 semigenome sequences of viruses of the C_2 cluster. The horizontal axis represents the position in the HXB2 genome of the midpoint of a $250 \mathrm{nt}$ window moving in 20 in increments, and the 
vertical axis represents the bootstrap value supporting clustering of the query sequence with subtype references. Vertical dashed lines denote breakpoint locations; (B) Mosaic structure of HIV-1 BC intersubtype circulating recombinant form (CRF108_BC). Breakpoint positions in the HXB2 genome are indicated.

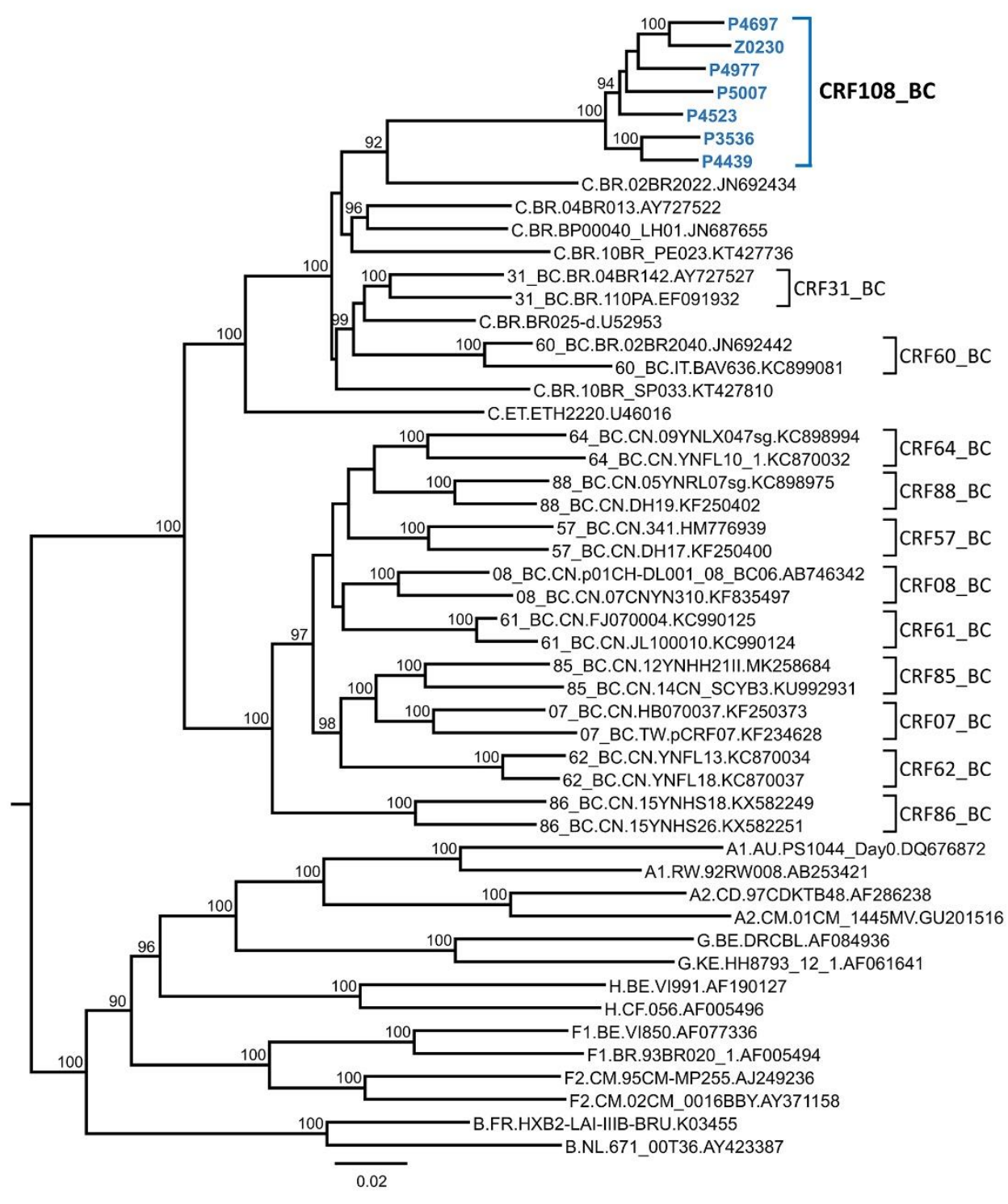

Figure 3. Maximum likelihood tree of NFLGs of CRF108_BC and all CRF_BCs identified to date. Only bootstrap values $\geq 90 \%$ are shown. CRF108_BC sequences are in blue and bold type. Database Scheme 108. BC, BLAST searches for similar sequences were done with subtype $C$ and B fragments at the Los Alamos HIV Sequence Database. With regard to the subtype $\mathrm{C}$ fragments, searches were done with the two largest fragments in gag-pol and tat-rev-vpu-env-nef, respectively. A phylogenetic tree with all subtype C concatenated fragments from the NFLGs of CRF108_BC, and most similar database sequences showed the closest relationship with the Brazilian virus 02BR2022 from Sao Paulo (Figure 4). Similarity searches with the four subtype B fragments and subsequent phylogenetic analyses with individual or concatenated fragments failed to identify any database virus related to the subtype B parental strain of CRF108_BC. 


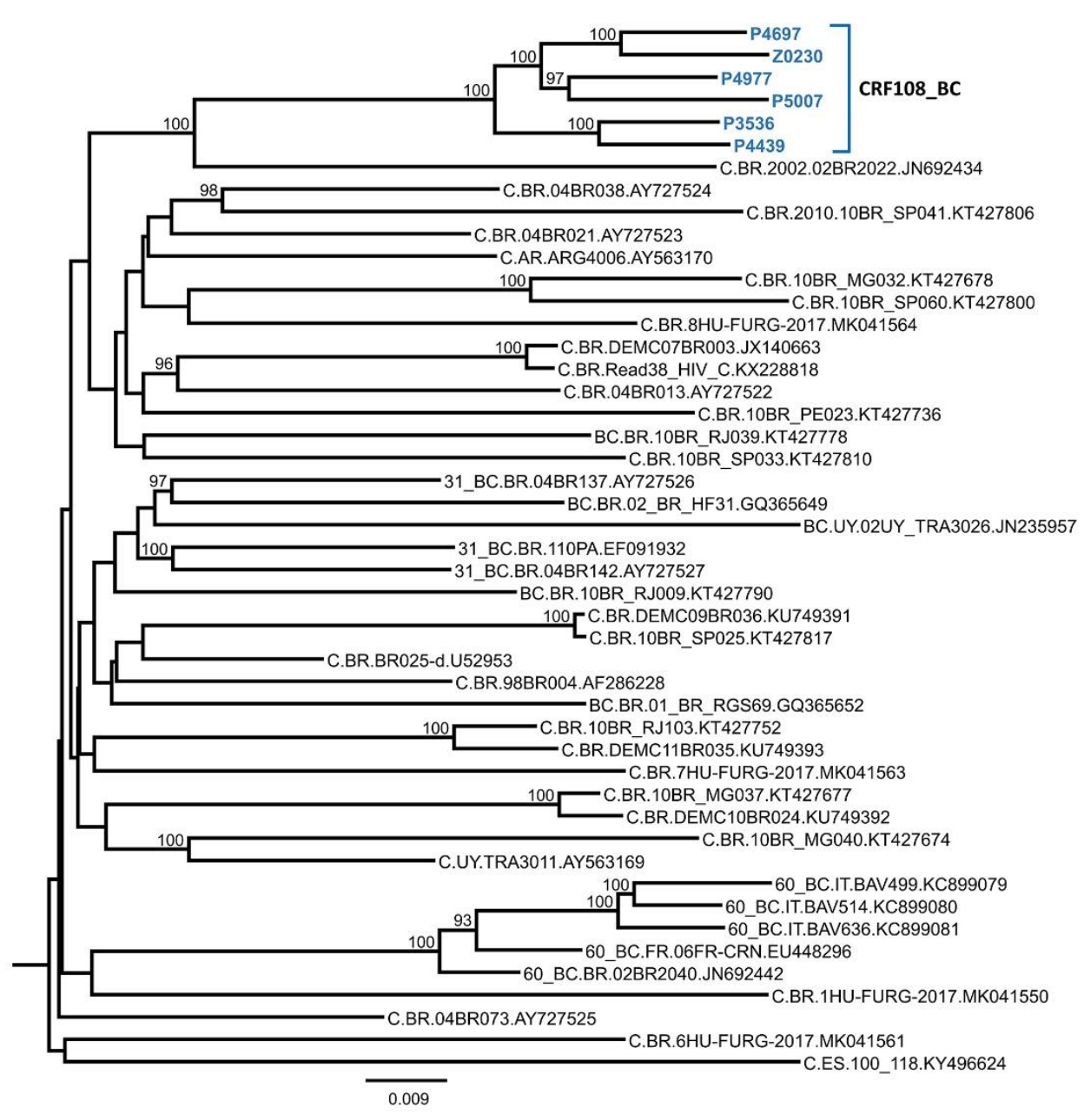

Figure 4. Phylogenetic tree of concatenated subtype C fragments of CRF108_BC. Only bootstrap values $\geq 90 \%$ are shown. CRF108_BC sequences are in blue and bold type. Database sequences are labeled with subtype, two-letter ISO code of the country of sample collection, virus name, and GenBank accession.

\subsection{Phylogeographic and Phylodynamic Analyses}

To estimate the temporal and geographic origin of CRF108_BC, a Bayesian coalescent analysis was performed with the 15 PR-RT sequences of the C_2 cluster and 50 subtype $C$ database sequences from different countries for which year and location of sample collection were available. Prior to this analysis, the existence of a temporal signal was checked with TempEst v1.5.1, which revealed a clock-like structure in the data set $\left(\mathrm{r}^{2}=0.38\right)$, indicating sufficient temporal signal to perform the analyses.

The tMRCA of the cluster was estimated around 2000 (95\% HPD, 1995-2004) in the city of Vitoria with a location posterior probability of 0.998 . An ancestry in Brazil was also strongly supported (Figure 5). 


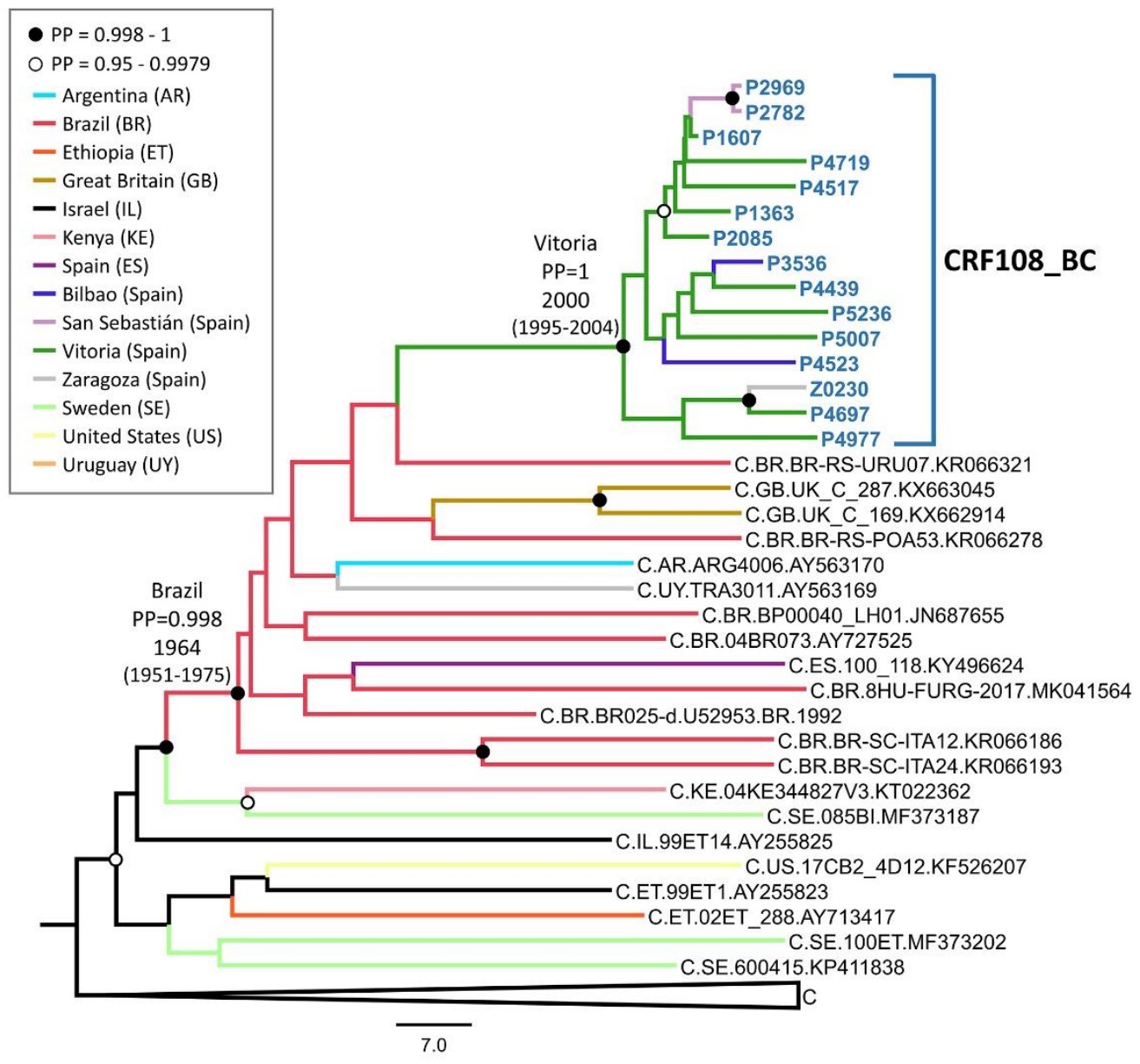

Figure 5. Maximum clade credibility tree of PR-RT sequences of CRF108_BC and 50 subtype C sequences from databases. Sequences belonging to the CRF108_BC cluster are in blue and bold type. Database sequences are labeled with subtype, two-letter ISO country-code, virus name, and GenBank accession. Colors of terminal and internal branches represent sampling locations and most probable locations of the corresponding nodes, respectively, according to the legend. For the nodes corresponding to the cluster and its closest ancestor, the most probable locations and the mean tMRCA (with 95\% HPD intervals) are indicated. Nodes supported by PP (posterior probability) $=0.998-1$ and PP $=0.95-0.9979$ are marked with filled and unfilled circles, respectively. 29 branches corresponding to sequences from Botswana, Cyprus, Ethiopia, Georgia, Israel, Kenya, Malawi, Senegal, South Africa, Sweden, Tanzania, United Kingdom, Yemen, and Zambia were collapsed for better viewing.

\section{Discussion}

The characterization of six HIV-1 NFLG sequences of BC recombinant viruses obtained from epidemiologically-unlinked patients showing a coincident mosaic structure different from previously identified CRFs and clustering with a $100 \%$ bootstrap value allowed to define a new CRF, designated CRF108_BC. Nine additional partial sequences are grouped in a monophyletic cluster in PR-RT. All 15 patients were diagnosed with HIV-1 infection in Northern Spain between 2006 and 2019 and were infected predominantly via heterosexual contact.

CRF108_BC is the first CRF recombinant of subtypes B and C parental strains identified in Spain and the second in Europe (after CRF60_BC in Italy [13]). Ten CRF_BCs have been identified elsewhere, nine in China [CRF07_BC [32], CRF08_BC [33], CRF57_BC [34], CRF61_BC [35], CRF62_BC [36], CRF64_BC [37], CRF85_BC [38], CRF86_BC [39] and CRF88_BC [40]] and one in Brazil [CRF31_BC [41]]. Similar to CRF60_BC, the subtype C parental strain of CRF108_BC is phylogenetically related to the subtype C strain circulating in Brazil. However, the recombination event giving rise to CRF108_BC could have occurred 
either in Brazil, where both B and C subtypes co-circulate at high proportions in some areas $[42,43]$ or in Spain, since we could not track the ancestry of the parental subtype B strain to any country. A Spanish origin of CRF108_BC would be supported by an inferred Spanish tMRCA in the city of Vitoria, Basque Country, Northern Spain, around 2000. However, we cannot rule out that CRF108_BC could be circulating at a low prevalence in some area(s) of Brazil, which could explain its lack of representation in public sequence databases.

CRF108_BC, similarly to all other CRF_BCs identified to date, is predominantly of subtype C. It is interesting to note that in all CRF_BCs, env is mostly of subtype C, which could lead to the speculation that a subtype $C$ envelope could confer evolutionary advantages regarding viral fitness, escape to immune response or a more efficient replication or transmission over a subtype B envelope. Further investigations are required to confirm any of these possibilities.

To date, the expansion of CRF108_BC has taken place from 2006 to 2019, with 53\% of cases diagnosed in the last 4 years, and limited to a small geographical area in Spain, with 10 of 15 cases in the city of Vitoria and 4 other cases in two neighboring provinces of the Basque Country. Outside of the Basque Country, we only have found a single infection with CRF108_BC in the city of Zaragoza among HIV-1 sequences from more than 13,000 patients from 10 regions of Spain analyzed by us and all sequences from public databases.

In Asia, the majority of CRF_BCs were transmitted initially among persons who inject drugs (PWID) [40,44] and recently expanded among MSM [45]. In Europe, CRF60_BC is associated with propagation among MSM [13]. Although, at present, MSM is the most frequent transmission route of HIV-1 in Spain [46], two CRFs previously identified in Spain, CRF14_BG and CRF73_BG, propagated mainly among PWID [7,15]. A third CRF identified in Spain, CRF47_BF, was associated with heterosexual transmission [10], similarly to CRF108_BC. However, we have observed further propagation of CRF47_BF among MSM [47]. This pattern could potentially be repeated with CRF108_BC since, along with heterosexually transmitted cases (with $27 \%$ women), we find an MSM diagnosed in 2017. This suggests that transmission networks of HIV-1 in Spain among heterosexuals may be drifting towards MSM. We have also observed the reverse situation in the case of a CRF02_AG cluster spreading from MSM to a heterosexual network [48].

NFLG sequencing of HIV-1 strains involved in expanding transmission clusters is highly recommendable in order to identify new CRFs, which may have acquired adaptive advantages through recombination $[49,50]$ even when recombination is not suspected in partial sequences, as it occurs with CRF108_BC. Genetic diversity and recombination are major obstacles to the development of an effective vaccine against HIV-1 [51-53]. Characterization and molecular epidemiological surveillance of expanding new HIV-1 CRFs may play an important role in public health actions, including the selection of optimal immunogens for effective vaccines.

\section{Conclusions}

A new HIV-1 CRF derived from subtypes B and C, designated CRF108_BC, has been identified after the analysis of six NFLG from three cities in Northern Spain, which was originally identified as a subtype C cluster in PR-RT sequences comprising 15 individuals. Phylogenetic and phylogeographic analyses point to a Brazilian ancestry, although it is unclear whether the recombination event took place in Brazil or in Spain.

Among CRFs derived from B and C subtypes, CRF108_BC is the 12th identified, the first in Spain and the second in Europe. Its spread is currently limited, with only 15 cases detected, most of them transmitted via heterosexual contact. Considering that more than half of them were diagnosed in the last four years, molecular epidemiological surveillance seems justified to examine further spread. The results of this study also advocate for NFLG sequence characterization of emerging HIV-1 clusters, which may represent new CRFs. 
Supplementary Materials: The following are available online at https://www.mdpi.com/1999 $-4915 / 13 / 1 / 93 / s 1$, Figure S1. Schematic depiction of NFLG amplification strategy. Figure S2. Comparison of the mosaic structure of CRF108_BC with those of previously reported CRF_BCs. Table S1. Primers used for amplification of PR-RT and NFLG sequences.

Author Contributions: Conceptualization, M.M.T., E.D., J.E.C.; methodology, J.E.C., E.D., M.M.T., H.G., M.S., S.B., E.G.-B., C.G.-G., A.C.-B., J.P.-Z., E.S.d.A., M.D.1.P., S.I., G.C., J.A.I., A.M.-S.; formal analysis, J.E.C., E.D., M.M.T.; investigation, J.E.C., E.D., M.M.T., H.G.; data curation, E.D., H.G.; writing-original draft preparation, J.E.C.; writing—review and editing, M.M.T., E.D., H.G.; supervision, M.M.T., E.D.; project administration, M.M.T., E.D.; funding acquisition, M.M.T., E.D. All authors have read and agreed to the published version of the manuscript.

Funding: This work was funded through Acción Estratégica en Salud Intramural (AESI), Instituto de Salud Carlos III, projects "Estudios sobre vigilancia epidemiológica molecular del VIH- 1 en España," PI16CIII/00033, and "Epidemiología molecular del VIH-1 en España y su utilidad para investigaciones biológicas y en vacunas", PI19CIII/00042; Red de Investigación en SIDA (RIS), Instituto de Salud Carlos III, Subdirección General de Evaluación y Fondo Europeo de Desarrollo Regional (FEDER), Plan Nacional I + D + I, project RD16ISCIII/0002/0004; and scientific agreement with Osakidetza-Servicio Vasco de Salud, Government of Basque Country, MVI 1001/16. JC was supported by the Social European Fund through the Youth Employment Operational Program and the Youth Employment Initiative and by the Comunidad de Madrid.

Institutional Review Board Statement: This study was carried out following the rules of the Declaration of Helsinki of 1975 and was approved by the Bioethics and Animal Well-being Committee of Instituto de Salud Carlos III, with protocol code CEI PI 38_2016-v3 (dated 20 June 2016).

Informed Consent Statement: Informed consent was obtained from all subjects involved in the study.

Data Availability Statement: The sequences newly obtained for this study are openly available at GenBank (https:/ /www.ncbi.nlm.nih.gov/genbank/) under accessions MT436238-MT436252, MT559130-MT559132, MN172222-MN172225.

Acknowledgments: We thank the personnel at that Genomic Unit at Instituto de Salud Carlos III for technical assistance in sequencing.

Conflicts of Interest: The authors declare no conflict of interest.

Ethics Statement: The study was part of the projects "Study on HIV-1 molecular epidemiological surveillance in Spain", funded by Instituto de Salud Carlos III (identification code PICIII16/00033), which was carried out following the rules of the Declaration of Helsinki of 1975 and was approved by the Bioethics and Animal Well-being Committee of Instituto de Salud Carlos III, with report number CEI PI 38_2016-v3 (dated 20 June 2016). All subjects gave their informed consent for inclusion before they participated in the study.

\section{References}

1. Faria, N.R.; Rambaut, A.; Suchard, M.A.; Baele, G.; Bedford, T.; Ward, M.J.; Tatem, A.J.; Sousa, J.D.; Arinaminpathy, N.; Pépin, J.; et al. The early spread and epidemic ignition of HIV-1 in human populations. Science 2014, 346, 56-61. [CrossRef] [PubMed]

2. Gryseels, S.; Watts, T.D.; Mpolesha, J.M.K.; Larsen, B.B.; Lemey, P.; Muyembe-Tamfum, J.J.; Teuwen, D.E.; Worobey, M. A near full-length HIV-1 genome from 1966 recovered from formalin-fixed paraffin-embedded tissue. Proc. Natl. Acad. Sci. USA 2020, 117, 12222-12229. [CrossRef] [PubMed]

3. Hemelaar, J.; Elangovan, R.; Yun, J.; Dickson-Tetteh, L.; Fleminger, I.; Kirtley, S.; Williams, B.; Gouws-Williams, E.; Ghys, P.D.; Abimiku, A.G.; et al. Global and regional molecular epidemiology of HIV-1, 1990-2015: A systematic review, global survey, and trend analysis. Lancet Infect. Dis. 2019, 19, 143-155. [CrossRef]

4. Robertson, D.L.; Anderson, J.P.; Bradac, J.A.; Carr, J.K.; Foley, B.; Funkhouser, R.K.; Gao, F.; Hahn, B.H. HIV-1 nomenclature proposal. Science 2000, 288, 55. [CrossRef] [PubMed]

5. Hofstra, L.M.; Sauvageot, N.; Albert, J.; Alexiev, I.; García, F.; Struck, D.; Van De Vijver, D.A.M.C.; Åsjö, B.; Kolupajeva, T.; Kostrikis, L.G.; et al. Transmission of HIV drug resistance and the predicted effect on current first-line regimens in Europe. Clin. Infect. Dis. 2016, 62, 655-663. [CrossRef] [PubMed]

6. Gao, F.; Robertson, D.L.; Carruthers, C.D.; Li, Y.; Bailes, E.; Kostrikis, L.G.; Salminen, M.O.; Bibollet-ruche, F.; Peeters, M.; Ho, D.D.; et al. An isolate of human immunodeficiency virus type 1 originally classified as subtype I represents a complex mosaic comprising three different group M subtypes (A, G, and I). J. Virol. 1998, 72, 10234-10241. [CrossRef] 
7. Delgado, E.; Thomson, M.M.; Villahermosa, M.L.; Sierra, M.; Ocampo, A.; Miralles, C.; Rodríguez-Pérez, R.; Diz-Aren, J.; Ojea-de Castro, R.; Losada, E.; et al. Identification of a newly characterized HIV-1 BG intersubtype circulating recombinant form in Galicia, Spain, which exhibits a pseudotype-like virion structure. JAIDS J. Acquir. Immune Defic. Syndr. 2002, 29, 536-543. [CrossRef]

8. Thomson, M.M.; Delgado, E.; Manjón, N.; Ocampo, A.; Villahermosa, M.L.; Mariño, A.; Herrero, I.; Cuevas, M.T.; Vázquez de Parga, E.; Pérez-Álvarez, L.; et al. HIV-1 genetic diversity in Galicia Spain: BG intersubtype recombinant viruses circulating among injecting drug users. AIDS 2001, 15, 509-516. [CrossRef]

9. Struck, D.; Roman, F.; De Landtsheer, S.; Servais, J.-Y.; Lambert, C.; Masquelier, C.; Venard, V.; Ruelle, J.; Nijhuis, M.; Schmit, J.-C.; et al. Near full-length characterization and population dynamics of the human immunodeficiency virus type I circulating recombinant form 42 (CRF42_BF) in Luxembourg. AIDS Res. Hum. Retrovir. 2015, 31, 554-558. [CrossRef]

10. Fernández-García, A.; Pérez-Álvarez, L.; Cuevas, M.T.; Delgado, E.; Muñoz-Nieto, M.; Cilla, G.; Iribarren, J.A.; Pinilla, M.; Ocampo, A.; Miralles, C.; et al. Identification of a new HIV type 1 circulating BF intersubtype recombinant form (CRF47-BF) in Spain. AIDS Res. Hum. Retrovir. 2010, 26, 827-832. [CrossRef]

11. Foster, G.M.; Ambrose, J.C.; Hué, S.; Delpech, V.C.; Fearnhill, E.; Abecasis, A.B.; Leigh Brown, A.J.; Geretti, A.M. Novel HIV-1 recombinants spreading across multiple risk groups in the United Kingdom: The identification and phylogeography of circulating recombinant form (CRF) 50-A1D. PLoS ONE 2014, 9, 1-10. [CrossRef] [PubMed]

12. Leoz, M.; Feyertag, F.; Charpentierd, C.; Delaugerree, C.; Wirden, M.; Lemeea, V.; Plantier, J.-C. Characterization of CRF56_cpx, a new circulating B/CRF02/G recombinant form identified in MSM in France. AIDS 2013, 27, 2309-2315. [CrossRef] [PubMed]

13. Simonetti, F.R.; Lai, A.; Monno, L.; Binda, F.; Brindicci, G.; Punzi, G.; Bozzi, G.; Violin, M.; Galli, M.; Zazzi, M.; et al. Identification of a new HIV-1 BC circulating recombinant form (CRF60_BC) in Italian young men having sex with men. Elsevier B.V. Infect. Genet. Evol. 2014, 23, 176-181. [CrossRef] [PubMed]

14. Monno, L.; Brindicci, G.; Lai, A.; Punzi, G.; Altamura, M.; Roberto, F.; Ladisa, N.; Saracino, A.; Balotta, C. An outbreak of HIV-1 BC recombinants in Southern Italy. Elsevier B.V. J. Clin. Virol. 2012, 55, 370-373. [CrossRef]

15. Fernández-García, A.; Delgado, E.; Cuevas, M.T.; Vega, Y.; Montero, V.; Sánchez, M.; Carrera, C.; López-Álvarez, M.J.; Miralles, C.; Pérez-Castro, S.; et al. Identification of an HIV-1 BG intersubtype recombinant form (CRF73-BG), partially related to CRF14-BG, which is circulating in Portugal and Spain. PLoS ONE 2016, 11, 1-14. [CrossRef]

16. Wirden, M.; De Oliveira, F.; Bouvier-alias, M.; Lambert-niclot, S.; Raymond, S.; Si-mohammed, A.; Alloui, C.; André-garnier, E.; Bellecave, P.; Malve, B.; et al. New HIV-1 circulating recombinant form 94: From phylogenetic detection of a large transmission cluster to prevention in the age of geosocial-networking apps in France, 2013 to 2017. Eurosurveillance 2019, 24, 1-10. [CrossRef]

17. Recordon-Pinson, P.; Alves, B.M.; Tumiotto, C.; Bellecave, P.; Bonnet, F.; Neau, D.; Soares, E.A.; Soares, M.A.; Fleury, H. A New HIV-1 circulating recombinant form (CRF98-cpx) between CRF06-cpx and subtype B identified in southwestern France. AIDS Res. Hum. Retrovir. 2018, 34, 1005-1009. [CrossRef]

18. Delgado, E.; Cuevas, M.T.; Domínguez, F.; Vega, Y.; Cabello, M.; Fernández-García, A.; Pérez-Losada, M.; Castro, M.Á.; Montero, V.; Sánchez, M.; et al. Phylogeny and phylogeography of a recent HIV-1 subtype F outbreak among men who have sex with men in Spain deriving from a cluster with a wide geographic circulation in Western Europe. PLoS ONE 2015, 10, 1-18. [CrossRef]

19. Sierra, M.; Thomson, M.M.; Ríos, M.; Casado, G.; Ojea-de Castro, R.; Delgado, E.; Echevarría, G.; Muñoz, M.; Colomina, J.; Carmona, R.; et al. The analysis of near full-length genome sequences of human immunodeficiency virus type $1 \mathrm{BF}$ intersubtype recombinant viruses from Chile, Venezuela and Spain reveals their relationship to diverse lineages of recombinant viruses related to CRF12_BF. Infect. Genet. Evol. 2005, 5, 209-2017. [CrossRef]

20. Shcherbakova, N.S.; Shalamova, L.A.; Delgado, E.; Fernández-García, A.; Vega, Y.; Karpenko, L.I.; Ilyichev, A.A.; Sokolov, Y.V.; Shcherbakov, D.N.; Pérez-Álvarez, L.; et al. Short communication: Molecular epidemiology, phylogeny, and phylodynamics of CRF63-02A1, a recently originated HIV-1 circulating recombinant form spreading in Siberia. AIDS Res. Hum. Retrovir. 2014, 30, 912-919. [CrossRef]

21. Price, M.N.; Dehal, P.S.; Arkin, A.P. FastTree 2-Approximately maximum-likelihood trees for large alignments. PLoS ONE. 2010, 5, 1-4. [CrossRef] [PubMed]

22. Karlin, S.; Altschul, S.F. Methods for assessing the statistical significance of molecular sequence features by using general scoring schemes. Evolution 1990, 87, 2264-2268. [CrossRef] [PubMed]

23. HIV Sequence Database 2020. Available online: http:/ / www.hiv.lanl.gov/ (accessed on 2 December 2020).

24. Trifinopoulos, J.; Nguyen, L.T.; von Haeseler, A.; Minh, B.Q. W-IQ-TREE: A fast online phylogenetic tool for maximum likelihood analysis. Nucleic Acids Res. 2016, 44, W232-W235. [CrossRef] [PubMed]

25. Salminen, M.O.; Carr, J.K.; Burke, D.S.; McCutchan, F.E. Identification of breakpoints in intergenotypic recombinants of HIV type 1 by bootscanning. AIDS Res. Hum. Retrovir. 1995, 11, 1423-1425. [CrossRef]

26. Lole, K.S.; Bollinger, R.C.; Paranjape, R.S.; Gadkari, D.; Kulkarni, S.S.; Novak, N.G.; Ingersoll, R.; Sheppard, H.W.; Ray, S.C. Full-Length Human Immunodeficiency Virus Type 1 Genomes from Subtype C-Infected Seroconverters in India, with Evidence of Intersubtype Recombination. J. Virol. 1999, 73, 152-160. [CrossRef]

27. Suchard, M.A.; Lemey, P.; Baele, G.; Ayres, D.L.; Drummond, A.J.; Rambaut, A. Bayesian phylogenetic and phylodynamic data integration using BEAST 1.10. Virus Evol. 2018, 4, 1-5. [CrossRef]

28. Rambaut, A.; Lam, T.T.; Max Carvalho, L.; Pybus, O.G. Exploring the temporal structure of heterochronous sequences using TempEst (formerly Path-O-Gen). Virus Evol. 2016, 2, 1-7. [CrossRef] 
29. Shapiro, B.; Rambaut, A.; Drummond, A.J. Choosing appropriate substitution models for the phylogenetic analysis of proteincoding sequences. Mol. Biol. Evol. 2006, 23, 7-9. [CrossRef]

30. Rambaut, A.; Drummond, A.J.; Xie, D.; Baele, G.; Suchard, M.A. Posterior summarization in Bayesian phylogenetics using Tracer 1.7. Syst. Biol. 2018, 67, 901-904. [CrossRef]

31. Liu, T.F.; Shafer, R.W. Web Resources for HIV Type 1 Genotypic-Resistance Test Interpretation. Clin. Infect. Dis. 2006, 42, 1608-1618. [CrossRef]

32. Su, L.; Graf, M.; Zhang, Y.; von Briesen, H.; Xing, H.; Kostler, J.; Melzl, H.; Wolf, H.; Shao, Y.; Wagner, R. Characterization of a Virtually Full-Length Human Immunodeficiency Virus Type 1 Genome of a Prevalent Intersubtype (C/B') Recombinant Strain in China. J. Virol. 2000, 74, 11367-11376. [CrossRef] [PubMed]

33. Piyasirisilp, S.; McCutchan, F.E.; Carr, J.K.; Sanders-Buell, E.; Liu, W.; Chen, J.; Wagner, R.; Wolf, H.; Shao, Y.; Lai, S.; et al. A recent outbreak of human immunodeficiency virus type 1 infection in southern China was initiated by two highly homogeneous, geographically separated strains, circulating recombinant form AE and a novel BC recombinant. J. Virol. 2000, 74, 11286-11295. [CrossRef] [PubMed]

34. Li, L.; Chen, L.; Yang, S.; Li, T.; Li, J.; Liu, Y.; Jia, L.; Yang, B.; Bao, Z.; Li, H.; et al. Recombination form and epidemiology of HIV-1 unique recombinant strains identified in Yunnan, China. PLoS ONE 2012, 7, 1-7. [CrossRef] [PubMed]

35. Li, X.; Ning, C.; He, X.; Yang, Y.; Li, F.; Xing, H.; Hong, K.; Yang, R.; Shao, Y. Genome sequences of a novel HIV-1 circulating recombinant form (CRF61_BC) identified among heterosexuals in China. Genome Announc. 2013, 1, 1-2. [CrossRef] [PubMed]

36. Wei, H.; His, J.; Feng, Y.; Xing, H.; He, X.; Liao, L.; Duan, S.; Ning, C.; Wang, N.; Takebe, Y.; et al. Identification of a novel HIV-1 circulating recombinant form (CRF62-BC) in western Yunnan of China. AIDS Res. Hum. Retrovir. 2014, 30, 380-383. [CrossRef] [PubMed]

37. Hsi, J.; Wei, H.; Xing, H.; Feng, Y.; He, X.; Liao, L.; Jia, M.; Wang, N.; Ning, C.; Shao, Y. Genome sequence of a novel HIV-1 circulating recombinant form (CRF64-BC) identified from Yunnan, China. AIDS Res. Hum. Retrovir. 2014, 30, 389-393. [CrossRef]

38. Su, L.; Wei, D.; Yang, H.; Zeng, Y.; Hu, Y.; Yuan, D.; Feng, L.; Ruan, Y.; Qin, G.; Liang, S. Identification of a novel HIV-1 circulating recombinant form (CRF85-BC) in Sichuan, China. AIDS Res. Hum. Retrovir. 2016, 32, 895-899. [CrossRef]

39. Li, Y.; Miao, J.; Miao, Z.; Song, Y.; Wen, M.; Zhang, Y.; Guo, S.; Zhao, Y.; Feng, Y.; Xia, X. Identification of a Novel HIV Type 1 Circulating Recombinant Form (CRF86-BC) among Heterosexuals in Yunnan, China. AIDS Res. Hum. Retrovir. 2017, 33, $279-283$. [CrossRef]

40. Hu, Y.; Wan, Z.; Zhou, Y.H.; Smith, D.; Zheng, Y.T.; Zhang, C. Identification of two new HIV-1 circulating recombinant forms (CRF87_cpx and CRF88_BC) from reported unique recombinant forms in Asia. AIDS Res. Hum. Retrovir. 2017, 33, 353-358. [CrossRef]

41. Santos, A.F.; Sousa, T.M.; Soares, E.A.J.M.; Sanabani, S.; Martínez, A.M.B.; Sprinz, E.; Silveira, J.; Sabino, E.C.; Tanuri, A.; Soares, M.A. Characterization of a new circulating recombinant form comprising HIV-1 subtypes $\mathrm{C}$ and B in southern Brazil. AIDS 2006, 20, 2011-2019. [CrossRef]

42. Brindeiro, R.M.; Díaz, R.S.; Sabino, E.C.; Morgado, M.G. Brazilian Network for HIV Drug Resistance Surveillance (HIV-BResNet): A survey of chronically infected individuals. AIDS 2003, 17, 1063-1069. [CrossRef] [PubMed]

43. Pessoa, C.; Farias, J.K.; Santos, V.M.; das Neves, C.A.; Feitosa, P.A.; Lima, K. HIV-1 subtype frequency in northeast Brazil: A systematic review and meta-analysis. J. Med. Virol. 2020, 1-11. [CrossRef]

44. Song, Y.; Feng, Y.; Miao, Z.; Wang, B.; Yang, M.; Zhang, A.-M.; Liu, L.; Xia, X. Near-full-length genome sequences of a novel HIV-1 circulating recombinant form, CRF01_AE/B' /C (CRF78_cpx) in Yunnan, China. AIDS Res. Hum. Retrovir. 2016, 32, 601-606. [CrossRef] [PubMed]

45. Chen, Z.W.; Liu, L.; Chen, G.; Cheung, K.W.; Du, Y.; Yao, X.; Lu, Y.; Chen, L.; Lin, X.; Chen, Z. Surging HIV-1 CRF07_BC epidemic among recently infected men who have sex with men in Fujian, China. J. Med. Virol. 2018, 90, 1210-1221. [CrossRef] [PubMed]

46. Dirección General de Salud Pública, Calidad e Innovación, Ministerio de Sanidad, Consumo y Bienestar Social. Vigilancia Epidemiológica del VIH y SIDA en España. 2019. Available online: https://www.mscbs.gob.es/ciudadanos/enfLesiones/ enfTransmisibles/sida/vigilancia/Informe_VIH_SIDA_20201130.pdf (accessed on 2 December 2020).

47. Delgado, E.; Benito, S.; Montero, V.; Sánchez, M.; Cañada, J.; García-Bodas, E.; Thomson, M. Molecular epidemiology and phylogeopraphy of HIV-1 CRF47_BF, which has expanded recently in Spain. In Proceedings of the 26th International HIV Dynamics \& Evolution, Cascais, Portugal, 24-27 May 2019, unpublished; conference communication.

48. Delgado, E.; Benito, S.; Montero, V.; Cuevas, M.T.; Fernández-García, A.; Sánchez-Martínez, M.; García-Bodas, E.; Díez-Fuertes, F.; Gil, H.; Cañada, J.; et al. Diverse large HIV-1 non-subtype B clusters are spreading among men who have sex with men in Spain. Front. Microbiol. 2019, 10, 1-19. [CrossRef] [PubMed]

49. Arenas, M.; Lorenzo-Redondo, R.; López-Galíndez, C. Influence of mutation and recombination on HIV-1 in vitro fitness recovery. Elsevier Inc. Mol. Phylogenet. Evol. 2016, 94, 264-270. [CrossRef]

50. Souza, J.S.M.; Silva Júnior, J.J.; Brites, C.; Monteiro-Cunha, J.P. Molecular and geographic characterization of HIV-1 BF recombinant viruses. Virus Res. 2019, 270, 1-10. [CrossRef]

51. Thomson, M.M. The Significance of HIV-1 Genetic Diversity for Vaccine Development. Curr. HIV Res. 2010, 8, 577-578. [CrossRef] 
52. Thomson, M.M.; Pérez-Álvarez, L.; Nájera, R. Molecular epidemiology of HIV-1 genetic forms and its significance for vaccine development and therapy. Lancet Infect. Dis. 2002, 2, 461-471. [CrossRef]

53. Hraber, P.; Korber, B.T.; Lapedes, A.S.; Bailer, R.T.; Seaman, M.S.; Gao, H.; Greene, K.M.; McCutchan, F.; Williamson, C.; Kim, J.H.; et al. Impact of clade, geography, and age of the epidemic on HIV-1 neutralization by antibodies. J. Virol. 2014, 88, 12623-12643. [CrossRef] 